\title{
ATUAÇÃO DAS PROFESSORAS SUPERVISORAS DO PIBID/UFSM/PEDAGOGIA: DESAFIOS DA GESTÃO ESCOLAR
}

http://dx.doi.org/10.5902/2318133820502

\author{
Rosane Carneiro Sarturi \\ Universidade Federal de Santa Maria, Brasil. \\ Nicole Zanon Veleda \\ Universidade Federal de Santa Maria, Brasil.
}

\begin{abstract}
Resumo
Neste texto apresenta-se um estudo sobre o impacto das ações do Pibid/UFSM/Pedagogia Anos Iniciais nas práticas das professoras supervisoras. Objetiva-se identificar a compreensão das professoras acerca do processo de gestão escolar a partir da sua contribuição como supervisoras do subprojeto nas escolas. A metodologia adotada é de abordagem qualitativa, do tipo estudo de caso. Para a coleta de dados utilizou-se questionários semi-estruturados. É possível concluir a relevância destas professoras como coformadoras das bolsistas de iniciação à docência, assim como a contribuição do subprojeto em suas vivências, como espaço de construção e reflexão de sua prática escolar.

Palavras-chave: pedagogia, políticas públicas, prática pedagógica, gestão escolar, iniciação à docência.

\section{THE PERFORMANCE OF THE SUPERVISORY TEACHERS FROM PIBID/UFSM/PEDAGOGY: SCHOOL MANAGEMENT CHALLENGES}

\begin{abstract}
The work presents a study about the Pibid/UFSM/Pedagogy impacts - Early Years in the practices of the supervisory teachers. The main objective is to identify the understanding of teachers about the school management process from their contribution to supervisors of the subproject in schools. The methodology used in this study was qualitative approach, case study, semi-structured questionnaires. It is possible to conclude the relevance of these teachers as tutors to the Introduction to Teaching scholarship and the subproject contribution on their experiences, such as construction and reflection of their school practice.

Key-words: pedagogy, public policy, teaching practice, school management, introduction to teaching.
\end{abstract}


ste trabalho tem como abordagem principal a identificação da compreensão
das professoras supervisoras do subprojeto da área da Pedagogia - Anos
Iniciais e a sua relação com os desafios encontrados na gestão da escola e do subprojeto, a partir de vivências enquanto bolsistas do Programa Institucional de Bolsas de Iniciação à Docência - Pibid.

O Programa Institucional de Bolsas de Iniciação à Docência - Pibid - é uma política pública nacional que surgiu como fomento à iniciação à docência, cujo objetivo é de que a educação básica pública brasileira seja de qualidade e que a formação inicial de professores no ensino superior seja aperfeiçoada a partir das interlocuções propostas por esta política. Dentre os objetivos do programa está a valorização do magistério, assim como a integração de professores da rede pública com os estudantes dos cursos de licenciatura das universidades.

O projeto institucional da Universidade Federal de Santa Maria, uma das universidades parceiras do programa, é formado por 19 subprojetos que contemplam a maioria dos cursos de licenciatura e também por subprojetos formados com estudantes de diferentes licenciaturas. Cada subprojeto possui sua proposta de inserção nas escolas, nos diferentes níveis da educação básica, e o grupo de bolsistas de iniciação à docência é coordenado por um professor da instituição de ensino superior, denominado coordenador de área. Além desse professor integram os subprojetos: estudantes das licenciaturas, bolsistas de iniciação à docência, e os professores da rede escolar pública, professor supervisor, responsável pelas interlocuções dos subprojetos com a escola em que atua e que participa do programa.

As ações do subprojeto da área da Pedagogia - Anos Iniciais nas escolas se concretizam por diferentes modalidades de inserção, proporcionando aos alunos espaços de aprendizagem diferenciados ao promover a interação dos conteúdos trabalhados em sala de aula com os saberes que os próprios alunos constroem.

Para assumir a função de professor supervisor do subprojeto da área da Pedagogia - Anos Iniciais é necessário que uma professora do quadro docente da escola se candidate em um edital específico do projeto institucional, indicando o subprojeto pretendido. Essa professora, ao se candidatar para atuar no subprojeto da área da Pedagogia - Anos Iniciais se propõe a fazer a organização do subprojeto, articulando o trabalho desenvolvido pelas bolsistas com a escola e suas demandas. A professora supervisora, portanto, é a gestora responsável pelo subprojeto dentro do ambiente escolar.

O trabalho desenvolvido na escola, fundamentado nos pressupostos epistemológicos de construção do conhecimento propostos pelo subprojeto da área da Pedagogia - Anos Iniciais, possibilitaram uma construção diferenciada da compreensão das atribuições do profissional da educação atualmente, que deve dar conta de muitas demandas, sem perder o foco no que é papel fundamental da escola: a qualificação do processo de ensino-aprendizagem dos alunos.

O grupo de bolsistas de iniciação à docência em cada escola era coordenado por uma das bolsistas, encarregada pelo contato tanto com a professora supervisora, representante da escola, quanto com a professora coordenadora de área. Essa bolsista, 
ao coordenar a organização da ação do grupo na escola, precisou lidar com situações referentes ao trabalho pedagógico, à relação entre colegas, entre outras, que influenciavam as ações desses sujeitos dentro do ambiente escolar.

Devido à aproximação e contato permanente com a professora supervisora que acompanhava as bolsistas e as ações desenvolvidas por este subprojeto, foi possível perceber que essas situações também eram recorrentes em seu âmbito na escola e que essa professora precisava intervir nessas questões em prol do bom funcionamento do subprojeto na escola.

O problema dessa pesquisa foi expresso nos seguintes termos: como as professoras percebem o processo de gestão escolar depois de atuarem como supervisoras do Pibid/Pedagogia?

Os objetivos foram: identificar como as professoras compreendem o processo de gestão escolar a partir da sua contribuição como supervisora do subprojeto da área da Pedagogia nas escolas; verificar como as professoras supervisoras percebem os possíveis impactos do Pibid/Pedagogia no processo de ensino-aprendizagem, considerando as percepções das regentes; entender como as supervisoras percebem a inserção do Pibid/Pedagogia no espaço escolar, considerando seu papel no processo.

\section{Metodologia}

Este trabalho foi desenvolvido com base nos pressupostos da pesquisa qualitativa, visto que esse tipo de pesquisa enfatiza aquilo que é subjetivo das pessoas, dando margem às percepções das mesmas acerca das relações construídas, únicas e individuais, em diferentes contextos. Minayo (1994, p. 21), apresenta a pesquisa qualitativa como uma pesquisa que "trabalha com o universo de significados, motivos, aspirações, crenças, valores e atitudes, o que corresponde a um espaço mais profundo das relações, dos processos e dos fenômenos que não podem ser reduzidos à operacionalização de variáveis".

$\mathrm{Na}$ tentativa de aprofundamento das relações, para uma melhor compreensão do ocorrido, utilizou-se uma pesquisa do tipo estudo de caso, que parte do interesse em verificar quais os impactos da participação destas professoras da rede pública no subprojeto da área da Pedagogia - Anos Iniciais, tanto em suas concepções acerca da gestão escolar, quanto das mudanças na sua prática pedagógica a partir desse contato com as estudantes bolsistas de iniciação à docência.

Segundo Gil (2002, p. 54), o estudo de caso "consiste no estudo profundo e exaustivo de um ou poucos objetos, de maneira que permita seu amplo e detalhado conhecimento, tarefa praticamente impossível mediante outros delineamentos já considerados".

A partir da experiência diária enquanto bolsista realizou-se uma busca na fundamentação legal do Programa Institucional de Bolsas de Iniciação à Docência em relação aos objetivos do mesmo. Nessa etapa da pesquisa focou-se a função de professor supervisor em sua descrição e atribuições da função, com a intenção de subsidiar a coleta e análise dos dados, bem como estabelecer relações com as observações enquanto bolsista de iniciação à docência. 
Tais observações foram realizadas durante todo o período em que o subprojeto esteve inserido na escola, pois a participação e o contato com a professora supervisora foi constante, nos anos de 2012 e 2013. Este estudo foi fundamental no sentido de compreender as especificidades do subprojeto que se constitui das normas gerais do Pibid.

A segunda etapa da pesquisa consistiu na coleta de dados por um questionário aberto. A escolha por este tipo de coleta de dados é justificada pelo fato de que o questionário

consiste basicamente em traduzir objetivos da pesquisa em questões específicas. As respostas a essas questões é que irão proporcionar os dados requeridos para descrever as características da população pesquisada ou testar as hipóteses que foram construídas durante o planejamento da pesquisa. (Gil, 2008, p. 121)

O questionário foi enviado por e-mail após contato com as professoras que foram supervisoras nas escolas participantes do Pibid. Sete professoras receberam 0 questionário por meio eletrônico, sendo que destas três responderam ao mesmo.

Uma dessas era professora supervisora do subprojeto em seu primeiro ciclo, dos anos de 2009 a 2011, e atuava, neste período, na coordenação pedagógica da escola. As outras duas professoras eram participantes do segundo ciclo, nos anos de 2012 e 2013, e atuavam em sala de aula em suas respectivas escolas.

Também se coletou dados a partir de observações participantes no cotidiano escolar, nos espaços de inserção do Pibid, pois se acredita que "as principais características do método dizem respeito ao fato de o pesquisador mergulhar de cabeça no campo, que observará a partir de uma perspectiva de membro, mas deverá, também, influenciar o que é observado graças a sua participação." (Flick, 2009, p. 207).

A etapa subsequente foi a análise do material coletado, estudo de referencial teórico da temática abordada e escrita do mesmo. A partir da interpretação do conteúdo dos questionários foi possível compreender a visão das professoras questionadas acerca das categorias de análise do presente trabalho em relação à relevância da sua atuação enquanto gestora em seu espaço de atuação profissional.

\section{O Pibid como política pública e sua relação com os docentes da educação básica}

Para compreender as interlocuções de docentes e estudantes proporcionadas pelo programa realizou-se a análise do edital do Programa Institucional de Bolsas de Iniciação à Docência - Pibid -, em relação aos objetivos gerais e às atribuições da função de professor supervisor, observando também os objetivos do subprojeto da área da Pedagogia.

O Pibid objetiva a qualificação da educação pública brasileira, com o incentivo à iniciação à docência, possibilitando a aproximação do estudante das licenciaturas com as diferentes realidades que podem ser encontradas no contexto escolar. 
No decreto n. 7.219 (Brasil, 2010, p. 4), de 24 de junho de 2010, o objetivo diretamente ligado ao contexto escolar está descrito no artigo $3^{\circ}$, inciso $\mathrm{V}$, no qual o programa tem como uma de suas diretrizes "incentivar escolas públicas de educação básica, mobilizando seus professores como co-formadores dos futuros docentes e tornando-as protagonistas nos processos de formação inicial para o magistério".

$\mathrm{Na}$ portaria n. 260, de dezembro de 2010, expedida pela Coordenação de Aperfeiçoamento de Pessoal de Nível Superior - Capes -, em que estão descritas as normas do Pibid, também estão descritos a definição e os requisitos para a participação como bolsista do programa. Os bolsistas supervisores são "professores das escolas públicas estaduais, municipais ou do Distrito Federal, participantes do projeto institucional apoiado, e designados para supervisionar as atividades dos bolsistas de iniciação à docência" (Capes, 2010).

Como requisitos para sua participação no programa o professor supervisor deve ser um profissional do magistério da educação básica, em efetivo exercício há pelo menos dois anos na escola da rede pública, preferencialmente atuando como professor regente em sala de aula. As atribuições, conforme edital, do cargo de supervisor são:

I. informar ao Coordenador de Área alterações cadastrais e eventuais mudanças nas condições que lhe garantiram inscrição e permanência no Pibid;

II. controlar a frequência dos bolsistas de iniciação à docência na escola, repassando essas informações ao Coordenador de Área do Programa;

III. acompanhar as atividades presenciais dos bolsistas de iniciação à docência sob sua orientação, em conformidade com o PIBID;

IV. participar de seminários regionais do Programa Institucional de Bolsa de Iniciação à Docência - PIBID, realizando as atividades previstas, tanto presenciais quanto a distância;

V. manter a direção e os demais integrantes da escola informados sobre a atuação e boas práticas pedagógicas geradas pelos bolsistas e

VI. elaborar e enviar ao Coordenador de Área documentos de acompanhamento das atividades dos bolsistas de iniciação à docência sob sua orientação, sempre que solicitado. (Capes, 2010, p. 9)

No primeiro edital, de 2007, o Pibid deu prioridade à sua inserção no ensino médio, nas áreas de Matemática, Química, Física e Biologia. No edital de 2009 houve a inserção de subprojetos das demais licenciaturas, com a intenção de ampliar a área de atuação do programa no ensino fundamental, em seus diferentes níveis.

Essa proposta, para o curso de Pedagogia da Universidade Federal de Santa Maria, surgiu como uma possibilidade de inserção na escola antes do estágio obrigatório, disciplina alocada nos últimos semestres do curso: oitavo semestre para a Pedagogia diurno e nono e décimo semestres para a Pedagogia noturno. Além da inserção no contexto escolar, ainda possibilita o efetivo exercício da escrita, no qual se realiza o exercício da reflexão sobre a prática, aliado ao conhecimento científico da academia.

O subprojeto da área da Pedagogia - Anos Iniciais da UFSM, que iniciou suas atividades no ano de 2009 e que até o ano de 2013 desenvolveu suas ações em seis diferentes escolas da rede pública municipal e estadual, contou com sete professores 
supervisores. Nesse período o subprojeto manteve um quadro de vinte e quatro bolsistas de iniciação à docência atuando nas escolas, além das bolsistas professoras supervisoras.

No primeiro ciclo, no período dos anos de 2009 a 2011, o Pibid/UFSM/Pedagogia atuou em três escolas, duas escolas da rede estadual e uma da rede municipal, processo que se repetiu no segundo ciclo, nos anos de 2012 e 2013.

Neste primeiro ciclo, de duração de dois anos previstos no edital, o subprojeto tinha como professores supervisores os sujeitos que ocupavam cargos na escola na direção, coordenação pedagógica e supervisão escolar. As bolsistas atuavam em todas as escolas, nas diferentes modalidades de inserção.

No segundo ciclo, durante a prorrogação do edital para mais dois anos, houve a mudança da professora coordenadora da área, que alterou também a organização do subprojeto. Com isso, as vinte e quatro bolsistas foram organizadas em subgrupos de oito bolsistas que compunham o grupo que atuaria em cada escola. Cada subgrupo era coordenado por uma bolsista mais experiente, que conhecia melhor as ações desenvolvidas no subprojeto. Nesse ciclo também se alterou o perfil do professor supervisor, pois todas as professoras atuavam na escola como regentes em sala de aula.

Nesses dois ciclos o subprojeto foi se reinventando para responder às demandas que surgiam nos contextos escolares. Foi possível o início da análise dos resultados que começavam a aparecer. Esses resultados, no subprojeto, se evidenciam na produção das bolsistas, como a elaboração de caderno didático, além de diversas participações em eventos nacionais e internacionais.

Todas as escolas que receberam o subprojeto da área da Pedagogia - Anos Iniciais possuíam o Índice de Desenvolvimento da Educação Básica - Ideb - abaixo da média e estavam localizadas em zonas periféricas da cidade, atendendo a crianças e jovens de classe média baixa e baixa, muitos dos quais se encontravam em situações de vulnerabilidade social.

O subprojeto possui três modalidades de inserção no ambiente escolar: a sala multidisciplinar e multisseriada - sala multi -, os ateliês e a formação de professores. Em todas as modalidades, a participação da professora supervisora é imprescindível como articuladora do trabalho desenvolvido pelas bolsistas com as demandas da escola.

A sala multi é um espaço alternativo de ensino e aprendizagem baseado na ludicidade que atende crianças e jovens de $2^{\circ}$ a $5^{\circ}$ anos do ensino fundamental, em três encontros semanais, no turno inverso ao regular. $O$ grupo de alunos atendidos apresentam dificuldades de aprendizagem ou defasagem idade-série, considerando os eixos de conhecimento trabalhados: raciocínio lógico-matemático, lecto-escrita e localização espaço-temporal, permeados pelas relações interpessoais.

As crianças e jovens que participam da sala multi são encaminhadas pelas professoras regentes das turmas por um parecer descritivo no qual escrevem sobre suas dificuldades de aprendizagem considerando os eixos de conhecimento já mencionados.

É necessário, para frequentar a sala multi, além dos pareceres descritivos da professora, a autorização dos pais, que devem estar cientes da participação de seu filho, assim como compreender a metodologia de trabalho utilizada. 
A professora supervisora é responsável por fazer com que os pareceres sejam preenchidos e encaminhados às bolsistas, organizadas reuniões com os pais desses alunos para explicar acerca do Pibid/Pedagogia, controlada a frequência dos alunos, assim como verificados os motivos daqueles que não comparecem aos encontros.

$\mathrm{O}$ ateliê é a modalidade na qual as bolsistas assumem a regência da sala de aula, uma vez por semana, ou quinzenalmente, de acordo com as demandas da escola, durante duas horas, em que trazem propostas diferenciadas de atividades, como jogos, trabalhos artísticos e outras atividades lúdicas, enquanto as professoras reúnem-se para um momento de formação continuada, em que podem trocar saberes com as colegas, organizar atividades integradas, planejar, entre outras atividades.

Nesse momento de formação continuada, está contida a modalidade de formação de professores. Nessa formação as bolsistas de iniciação à docência organizam oficinas e palestras sobre assuntos de interesse das professoras ou de demandas observadas na escola. Para que essa interação com o corpo docente ocorra, a professora supervisora se mostra como principal articuladora, pois como transita nos dois grupos, consegue contribuir para que a formação de professores, da qual também participa seja de relevância efetiva para todos envolvidos no processo.

Da maneira como este subprojeto se configura, o papel das professoras supervisoras, enquanto elo entre as ações das bolsistas de iniciação à docência e demais sujeitos da escola, se faz essencial para "acompanhar as atividades presenciais dos bolsistas de iniciação à docência sob sua orientação, em conformidade com o PIBID" (Capes, 2010, p. 9) no sentido de tornar significativas as ações do subprojeto para os sujeitos que estão envolvidos.

Atualmente temos uma realidade na qual os docentes da escola são oriundos de outras regiões da cidade, trabalham em mais escolas, de modo que não conseguem participar efetivamente da vida da comunidade escolar e das atividades do entorno da escola. Suas ações se restringem às práticas pedagógicas em sala de aula, pela impossibilidade de participação nas reuniões e em outras oportunidades de compartilhar informações, restando ao professor um tempo muito curto para compreender o que acontece na escola.

Tendo a universidade outra dinâmica, ou seja, outro tempo e outro espaço em que as relações acontecem, a professora supervisora exerce um papel fundamental para mediar a comunicação destes tempos harmonicamente, visando superar desafios e atingir objetivos em comum.

Este aspecto ilustra um dos pressupostos fundamentais na transição da concepção de administração escolar para gestão educacional. Lück (2006, p. 55) afirma que tal transição

pressupõe um entendimento diferente da realidade, dos elementos envolvidos em uma ação e das próprias pessoas em seu contexto; abrange uma série de concepções, tendo como foco a interatividade social, não consideradas pelo conceito de administração, e portanto, superando-a.

Como a gestão educacional requer participação de todos os sujeitos que compõem a escola, as ações da professora supervisora também visam à comunicação das práticas do Pibid para as demais professoras, de acordo com o previsto no inciso $\mathrm{V}$ do subitem 
8.3.1, da portaria n. 260: "manter a direção e os demais integrantes da escola informados sobre a atuação e boas práticas pedagógicas geradas pelos bolsistas" (Capes, 2010, p. 9), para que ocorra um entrelaçamento entre a proposta da escola com a proposta do subprojeto, quando um trabalho vem a somar com o outro que está em realização.

É possível perceber esse entrelaçar de propostas nas mostras pedagógicas das escolas, nas quais também há a participação do subprojeto, momento em que a comunidade tem a possibilidade de visitar a escola e acompanhar o trabalho desenvolvido nos muitos lugares em que o processo de ensino e aprendizagem é contemplado de forma diversa e diversificada.

A relevante contribuição das professoras supervisoras para que as ações do subprojeto se tornassem significativas para toda a comunidade escolar estão diretamente ligadas às concepções da gestão da escola e ao nível de entendimento que a escola possuía do subprojeto.

Pelo conteúdo dos questionários foi possível observar que as ações deste subprojeto, muitas vezes, não eram valorizadas pela direção da escola, assim como por parte do corpo docente, já que desconheciam o trabalho desenvolvido pelas bolsistas. A professora supervisora, por acompanhar o desenvolvimento das atividades, conhecia a relevância do trabalho realizado, mas fazer com que o trabalho interessasse ao restante do grupo era uma tarefa mais árdua.

Foi possível observar nas escolas participantes do subprojeto da área da Pedagogia - Anos Iniciais que os professores não conheciam os seus objetivos, ignorando todos os preceitos que orientavam a prática do subprojeto na escola. Como já mencionado, a realidade dos professores não facilitava esse processo de conhecimento da proposta deste subprojeto, assim como o reconhecimento da validade da proposta.

A reflexão acerca do papel do professor supervisor, suas dificuldades e suas possibilidades, leva às concepções de gestão escolar para além da equipe diretiva e um reconhecimento de identidade do professor enquanto gestor do espaço escolar, ou seja, seu papel que transcende a regência de classe.

\section{O professor supervisor assumindo-se gestor}

Durante a formação docente inicial a questão da gestão escolar é muito abordada na intenção de que os estudantes compreendam a relevância desse processo como fator fundamental para um funcionamento harmônico das escolas e dos processos que lhe são característicos, no que se trata das práticas pedagógicas e das questões administrativas, que fazem parte deste cotidiano.

Entretanto, o que se observa nas escolas, é que grande parte do corpo docente não se identifica como gestor daquele espaço. Os professores que atuam em sala de aula responsabilizam a equipe diretiva por tudo aquilo que dá errado na escola, alheios ao que acontece fora de seus domínios, da sua sala de aula.

Quando a proposta do subprojeto da área da Pedagogia - Anos Iniciais chega às escolas e que um professor de sala de aula assume a supervisão do projeto, mediante sua participação em edital específico, essa condição é aceita pela vontade de participar do Pibid pela possibilidade de qualificar o processo de ensino e aprendizagem dos alunos, assim como fornecer espaços de formação continuada a seus professores. Entretanto, ao 
iniciar as ações do subprojeto na escola existem alguns conflitos que precisam ser resolvidos pela professora supervisora, pois atribuir algum poder de gestor a uma professora é incomum.

Essa negação da autonomia à professora em questões relacionadas ao subprojeto é frequente, pois, geralmente questões que não são resolvidas em sala de aula são repassadas para a função exclusivamente competente para solucionar tal conflito ou problema, como o coordenador pedagógico, por exemplo.

Essa falta de compreensão causava tensão entre os professores, que exigiam respostas imediatas da professora supervisora, que tampouco conseguia fazê-los entender a epistemologia adotada pelo subprojeto, ou seja, a falta de conhecimento dos pressupostos que embasavam as práticas pedagógicas desenvolvidas nos espaços de inserção do Pibid resultava em uma disparidade entre métodos e concepções da construção do conhecimento, trazendo adversidades ao processo de cada aluno.

Heloísa Lück (2006) destaca que a ação conjunta e participativa se associa a uma autonomia competente, pois,

a gestão educacional cultiva relações democráticas, fortalecendo princípios comuns de orientação, norteadores da construção da autonomia competente, que se garantem a partir do estabelecimento e cumprimento de normas, leis, princípios e diretrizes comuns. Estas, quando entendidas em seu sentido e espírito pleno, são vistas em seu potencial de inspiração para dar unidade e organicidade ao conjunto de ações sociais. (p. 45)

O sentido de unidade trazido pela autora não se faz recorrente no contexto de muitas escolas, mais especificamente tratando-se das escolas em que foram vivenciadas as experiências em questão neste trabalho. A escola possui muitos elementos constitutivos que a tornam singular e que devem ser levados em consideração na construção de quaisquer projetos executados em seu cotidiano, no entanto, estes se manifestam de modo isolado em ações pontuais, esporádicas e independentes, o que os tornam demasiadamente enfraquecidos e cuja finalidade termina em si mesma.

A autora também elenca princípios que devem orientar prática de autonomia em gestão escolar. Neste sentido, a mobilização coletiva é um destes princípios:

Os processos de transformação associados à ação autônoma somente ocorrem mediante ação compartilhada e coletiva. O princípio é o de que a ação individual só é eficaz caso associada a outras ações. Boa ação é aquela que se integra a outras e não a que é isolada. Em vista disso, trabalha bem quem, através de suas ações, mobiliza o interesse, a atenção e a ação de outros para o mesmo fim. (Lück, 2006, p. 108)

Ou seja, o individualismo caracteriza a cultura escolar autoritária que não fortalece o processo educacional, fugindo de seu caráter complexo que abrange desde questões gerais da escola, até questões exclusivas de turmas, alunos, famílias. Nesta cultura autoritária, os papéis dos gestores ainda são pontuais e desconectados do cotidiano da sala de aula, bem como os professores não se envolvem em questões para além da sua própria sala de aula. 
É possível identificar a falta de reconhecimento pelos professores de sua identidade enquanto gestores do espaço escolar, independentemente de onde desenvolvam suas ações, seja como gestor na prática pedagógica em sala de aula, seja como gestor pedagógico ou administrativo, ao assumir um cargo na equipe diretiva ou outro setor da escola. Desta forma,

a identidade não é algo imutável. Nem externo, que possa ser adquirido. Mas é um processo de construção do sujeito historicamente situado. A profissão de professor, como as demais, emerge em dado contexto e momento históricos, como resposta a necessidades que estão postas pelas sociedades, adquirindo estatuto de legalidade. (Pimenta, 2000, p. 18)

As necessidades da escola no momento em que se vive apontam cada vez mais para professores que se reconheçam como gestores, que além de reconhecerem-se façam valer sua participação com ações de formação de parcerias, autogestão, trabalho em equipe, valorização do diálogo, compartilhamento de responsabilidades e comprometimento, conforme os princípios orientadores da gestão democrática indicados como diretrizes da educação nacional.

Com base nisso, a professora supervisora do Pibid caracteriza-se por um elemento chave na efetivação da gestão democrática no âmbito do subprojeto da área da Pedagogia-Anos Iniciais, tendo em vista que promove o diálogo entre a escola e uma ação que, além de surgir do exterior, ainda intervém na rotina da mesma, promovendo a possibilidade de estreitar os laços entre estes dois segmentos de um mesmo contexto, pois,

entender a organização escolar como cultura significa dizer que ela é construída pelos seus próprios membros [...] Membros que tanto podem criar um espaço de trabalho produtivo e até prazeroso ou um espaço hostil e estressante. Não estamos afirmando que na escola não devam existir conflitos, diferenças, interesses pessoais, interesses de poder. Eles existem e, por isso mesmo, é que convêm instalar uma prática de participação, de negociação dos significados e valores, de debate, de discussão pública dos compromissos e dificuldades. (Libâneo, 2008, p. 232)

Os desafios encontrados e superados pelas professoras supervisoras surgem para demonstrar o quanto tais sujeitos se sentiram parte do processo de consolidação deste subprojeto na sua escola pelas práticas de diálogo, que consideram todos que estão envolvidos na sua implementação. A proposta do subprojeto da área da Pedagogia-Anos Iniciais possibilita que essas professoras vislumbrem um novo sentido no processo de ensinar e aprender, assim como uma ressignificação ao seu conceito de escola.

Uma nova concepção de gestão começa a ser delineada pelas professoras a partir da participação como supervisoras deste subprojeto, cujo requisito é um movimento diferenciado, que incentiva ao repensar sua prática, não pela conscientização de mudanças pregado pela escola, mas pelo implícito desejo de compreender uma escola que, enfim, trata abertamente da educação em seus princípios legais, que tem por "finalidade o pleno desenvolvimento do educando, seu preparo para o exercício da cidadania e sua qualificação para o trabalho" (Brasil, 1996). 
A valorização do magistério torna-se uma realidade a partir do momento em que as professoras supervisoras usam suas vivências para subsidiar novas práticas e diferentes maneiras de lidar com a realidade da escola, principalmente da escola pública, com recursos escassos, que atende crianças e jovens inseridos em um contexto de vulnerabilidade, que interfere pontualmente em seu processo de ensino e aprendizagem.

Cientes desse movimento que precisam despertar no ambiente escolar e, apoiadas pelo subprojeto da área da Pedagogia-Anos Iniciais, as professoras participantes do subprojeto superam suas concepções a favor de qualificar o seu ambiente de trabalho, a sua relação com os alunos e com seus colegas. Nesse sentido, a articulação entre a universidade e a escola apresenta um espaço para que possibilidades de um novo trabalho se constituam.

\section{Interlocuções universidade-escola: algumas possibilidades}

As professoras supervisoras do subprojeto da área da Pedagogia - Anos Iniciais são articuladoras das ações deste subprojeto com a escola, para que as ações pedagógicas das bolsistas de iniciação à docência consigam ser realizadas na escola e que tais práticas desenvolvidas causem transformações significativas no contexto escolar.

O espaço escolar é considerado, muitas vezes, pelos estudantes de Pedagogia, um lugar que não permite muita interação, em que se barra a entrada desses sujeitos em formação, que em um futuro próximo estarão atuando nesse espaço. Em contrapartida as escolas alegam que, ao abrir as portas para esses estudantes, os mesmos vão ao espaço escolar, observam e realizam intervenções e não dão nenhum tipo de retorno para a escola, transformando a escola em um lugar de pesquisa que não merece saber aquilo que se pensou e observou nesse ambiente. Também resultado do afastamento entre saberes produzidos na escola e na universidade, vê-se a universidade como fonte de soluções aos problemas e dilemas escolares.

O Pibid, ao possibilitar a antecipação do contato entre estudantes e o ambiente escolar, compreendido como lugar para exercício da docência e da cidadania, quebra com esse estigma de que os estudantes aproveitam a escola sem dar nenhum tipo de retorno e de que a escola não possa ter participação ativa e ser motivo de preocupação dentro da universidade.

A escola é uma instituição que recebe e oportuniza áreas de atuação para muitos cursos. Além da área da educação também existem as intervenções de diversos profissionais da área da saúde. Porém, mesmo que ofereça essas oportunidades, a escola não consegue inserir-se na universidade, com exceção daqueles professores que buscam participar de projetos de pesquisa e extensão, por interesse em sua formação continuada.

No contexto do Pibid, além de promover espaços de formação aos estudantes das licenciaturas no local de atuação profissional, há trocas de experiências com professores que atuam na escola e que demonstram o interesse de estabelecer essas trocas, ou seja, que compreendem este espaço cedido à universidade como uma oportunidade de fortalecer seus conhecimentos e contribuir no processo de formação de futuros colegas professores. 
Essa articulação promovida pela professora supervisora traz benefícios para os sujeitos envolvidos, que podem ser observados em aspectos que vão do global para 0 local e vice-versa: as mudanças se fazem significativas, pois atingem um grande número de pessoas; atingem a prática dos professores, influenciam o processo de ensinoaprendizagem e transformam a formação inicial das bolsistas de iniciação à docência em momento de construção da profissionalidade docente. Libâneo, Oliveira e Toschi (2007, p. 377) afirmam que "o despreparo profissional pode estar associado, também, a uma frágil formação inicial, de modo que se faz necessário investir nas situações de trabalho, em maior conhecimento teórico, envolvendo tanto os saberes pedagógicos como os específicos".

Tendo em vista qualificar a formação inicial dos estudantes envolvidos, a antecipação do vínculo com o universo escolar dos estudantes de licenciaturas promove a articulação entre teoria e prática durante todo o tempo de participação no programa, além de promover um resgate dos saberes estudantes por parte das professoras participantes.

É relevante salientar, em função das reflexões que surgem com os dados da pesquisa, a mudança declarada das professoras nas suas práticas pedagógicas, da compreensão dos princípios epistemológicos que regem um trabalho diferenciado, que efetivamente traz resultados à aprendizagem dos alunos que, por sua vez, incentivam a professora à renovação de metodologias e de aceitação de possibilidades no que tange à construção do conhecimento.

$\mathrm{Na}$ inserção na escola as estudantes têm a possibilidade de relacionar os saberes teóricos e aplicá-los em suas ações pedagógicas, antecipando o contato com o ambiente escolar, que só ocorreria nos semestres finais do curso, durante a realização do estágio supervisionado. Ao chegar ao estágio com poucas oportunidades de inserção na escola, excetuando aquelas que trabalhavam em ambientes escolares, as estudantes se confrontam com um ambiente diferente daquele descrito durante o curso, em que os planejamentos e ações eram pensados para alunos ideais.

A escola - homogênea, acessível a todos e democrática - se revela um lugar hierarquizado, meritocrático e excludente. A gestão escolar é organizada e pensada por poucos, se usa um sistema de recompensa por maior e melhor produção, tanto para os alunos, quanto para os professores e ao afirmar que todos os sujeitos são iguais, se ignora a subjetividade que caracteriza a cada um. Assim,

do ponto de vista macro, verifica-se ser necessário haver modificações sensíveis na organização e orientação da educação brasileira, a fim de que se promova no país educação em nível de qualidade tal que este possa participar ativamente do processo de globalização da economia e internacionalização cultural; a fim de que o povo brasileiro não fique à margem do desenvolvimento, como também possa contribuir para o mesmo e usufruir desse movimento geral. Assim, por justiça, todos possam ter experiências educacionais estimulantes e promotoras do seu desenvolvimento integral. (Lück, 2006, p. 42)

As novas demandas da sociedade exigem um novo paradigma de relacionamento entre a própria sociedade e a escola, enquanto instituição nela inserida, de modo que se reconheça a interdependência com as influências culturais presentes no funcionamento da sociedade. 
Neste movimento os futuros profissionais da educação encontram-se no centro das mudanças requeridas há bastante tempo. Essa reforma paradigmática que envolve a escola, assim como toda a sociedade, atribui ao novo professor funções sociais que ultrapassam a barreira da sala de aula.

Com isso, a intencionalidade deste subprojeto atende às necessidades do próprio curso de Pedagogia, quando possibilita a antecipação do vínculo com o espaço escolar, assim como a compreensão da sistemática das relações que se estabelecem dentro da escola, dos interesses que regem as atitudes dos sujeitos desses espaços. $O$ ato de antecipar o contato do estudante com a escola fortalece a criação do vínculo profissional, assim como a responsabilidade de atuar nesse espaço.

\section{Considerações finais}

Foi possível verificar a relevância da participação efetiva da professora supervisora, reforçando a qualidade que é intrínseca às relações que se estabelecem a partir da inserção no subprojeto da área da Pedagogia do Programa Institucional de Bolsas de Iniciação à Docência - Pibid.

Pela análise do material coletado se percebe que o subprojeto da área da Pedagogia - Anos Iniciais conseguiu responder às demandas que apareceram no contexto escolar. Como já mencionado, a escola atual, assim como a sociedade em que esta instituição se insere e cujos preceitos também cultiva, vem atribuindo diversas funções aos profissionais que atuam nesse contexto.

As crianças e jovens atendidos pelo subprojeto da área da Pedagogia - Anos Iniciais exemplificam essas múltiplas carências que a escola situada na periferia precisa dar conta em um tempo curto, com poucos recursos, financeiros e de pessoal, e muitas vezes realizando ações para as quais não estavam preparados.

O Pibid fomenta a iniciação à docência dos alunos de licenciaturas para que vínculos sejam estabelecidos com a escola pública de educação básica, para que tais estudantes, ao tornarem-se profissionais, sintam-se desejosos de voltar para esse contexto e realizar intervenções que qualifiquem todos os processos que constituem essa instituição.

Para os profissionais que já atuam na escola e que tem a possibilidade de identificar nos estudantes o vigor de considerar a escola como uma novidade em suas práticas, a inserção do programa nesse ambiente pode facilitar o processo de busca permanente pela formação. Da mesma maneira, imbricar toda a carga teórica dos estudos na universidade com a prática desenvolvida na escola, se torna mais significativo quando o estudante pode aplicar esses conhecimentos em situações reais. É relevante ao professor a possibilidade de reinventar sua prática, apoiando-a em diferentes teorias, que não estavam em evidência durante sua formação inicial.

Ao vivenciar as experiências enquanto bolsista de iniciação à docência e, com elas, constituir parte da identidade profissional, percebe-se como é importante que a escola compreenda esse processo de formação. A professora supervisora, portanto, além de formar-se e identificar-se enquanto gestora do espaço que ocupa na escola e ciente da relevância das suas ideias para transformar esse espaço, se mostra como peça 
fundamental ao subprojeto, quando também se reconhece como coformadora das bolsistas, proporcionando às mesmas vivências que não lhes são possíveis dentro do contexto de estudante.

\section{Referências}

BRASIL. Lei de diretrizes e bases da educação nacional: Lei n. 9.394, de 20 de dezembro de 1996. Estabelece as diretrizes e bases da educação nacional [recurso eletrônico]. Brasília: Câmara dos Deputados, 2013.

BRASIL. Decreto n. 7.219, de 24 de junho de 2010. Dispõe sobre o Programa Institucional de Bolsa de Iniciação à Docência - PIBID e dá outras providências. Diário Oficial da União, n. 120, seção 1, p. 4-5, 2010. Disponível em <https://www.capes.gov.br/images/ stories/download/diversos/DecretoPIBID_240610.pdf>. Acesso em 10 jun. 2014.

CAPES. Portaria n. 260, de 30 de dezembro de 2010. Aprova as normas gerais do Programa Institucional de Bolsa de Iniciação à Docência - PIBID. Disponível em <http://www.capes.gov.br/educacao-basica/capesPibid/editais-e-selecoes>. Acesso em 10 jun. 2014.

FLICK, Uwe. Introdução à pesquisa qualitativa. Porto Alegre: Artmed, 2009.

GIL, Antônio Carlos. Como elaborar projetos de pesquisa. São Paulo: Atlas, 2002.

GIL, Antônio Carlos. Métodos e técnicas de pesquisa social. São Paulo: Atlas, 2008.

LIBÂNEO, José Carlos; OLIVEIRA, João Ferreira; TOSCHI, Mirza Seabra. Educação escolar: políticas, estrutura e organização. São Paulo: Cortez, 2007.

LIBÂNEO, José Carlos. Organização e gestão da escola: teoria e prática. Goiânia: MF, 2008.

MINAYO. Cecília de Souza. Ciência, técnica e arte: o desafio da pesquisa social. In: DESLANDES, Suely Ferreira. Pesquisa social: teoria, método e criatividade. Petrópolis: Vozes, 1994, p. 9-29.

PIMENTA, Selma Garrido. Saberes pedagógicos e atividade docente. São Paulo: Cortez, 2000.

Rosane Carneiro Sarturi é professora no Departamento de Administração Escolar do Centro de Educação da Universidade Federal de Santa Maria, coordenadora do Programa de Pós-Graduação em Políticas Públicas e Gestão Educacional e atua no Programa de Pós-Graduação em Educação.

Endereço: Expedicionário Almeida, 252 - 97400-000 - São Pedro do Sul - RS Brasil.

E-mail: rcsarturi@gmail.com.

Nicole Zanon Veleda é pedagoga, professora da Rede Municipal de Ensino de Santa Maria e estudante do Curso de Especialização em Gestão Educacional na Universidade Federal de Santa Maria.

Endereço: Rua Elídio Ribeiro, 215 - 97070-114 - Santa Maria - RS - Brasil.

E-mail: nicolezveleda@gmail.com.

Recebido em 20 de novembro de 2015.

Aceito em 29 de março de 2016. 